\title{
Madeleine De Scudery, Clélie. Histoire romaine. Troisième partie - 1657
}

\section{Chiara Rolla}

\section{(2) OpenEdition}

1 Journals

\section{Edizione digitale}

URL: https://journals.openedition.org/studifrancesi/39286

DOI: 10.4000/studifrancesi.39286

ISSN: 2421-5856

\section{Editore}

Rosenberg \& Sellier

\section{Edizione cartacea}

Data di pubblicazione: 1 décembre 2004

Paginazione: 360

ISSN: 0039-2944

\section{Notizia bibliografica digitale}

Chiara Rolla, «Madeleine De Scudery, Clélie. Histoire romaine. Troisième partie - 1657», Studi Francesi [Online], 143 (XLVIII | II) | 2004, online dal 30 novembre 2015, consultato il 19 mai 2021. URL: http:// journals.openedition.org/studifrancesi/39286 ; DOI: https://doi.org/10.4000/studifrancesi.39286

Questo documento è stato generato automaticamente il 19 mai 2021.

\section{(c) $(1) \&$}

Studi Francesi è distribuita con Licenza Creative Commons Attribuzione - Non commerciale - Non opere derivate 4.0 Internazionale. 


\section{Madeleine De Scudery, Clélie. Histoire romaine. Troisième partie - 1657}

Chiara Rolla 
NOTIZIA

MADELEINE DE SCUDERY, Clélie. Histoire romaine. Troisième partie - 1657, édition critique par CHANTAL MORLET-CHANTALAT, Paris, Champion, 2003, p. 567.

1 La terza parte della Clélie, pubblicata nel 1657, costituisce una tappa importante dell'itinerario letterario e sociale di Madeleine de Scudéry e, al tempo stesso, offre lo spaccato di un'epoca molto interessante, coincidente con la metà del XVII secolo.

questo periodo la romanziera frequenta l'Hôtel de Nevers, uno dei centri culturali più importanti della capitale, e qui affina la sua riflessione sull'amore galante e la «tendre amitié». In questa terza parte, infatti, le conversazioni si trasformano in scambi più generali sulla vita di società e su un dibattito, destinato ad essere ripreso anche da Molière, sull'arte di piacere.

Evidente è l'influsso dell'umanista Pellisson, figura presente sotto le spoglie di Herminius, protagonista dell'«Histoire d'Herminius et de Valérie».

4 La terza parte della Clélie si distingue inoltre per l'uso di una traduzione più recente delle Decadi di Tito Livio, sempre ad opera di Du Ryer, e per un legame ancora più stretto con la tradizione retorica. Numerosi sono anche i riferimenti all'Astrée, soprattutto nei libri 2 e 3.

5 Si può allora concludere con la Morlet-Chantalat, autrice di questa notevole impresa che sta restituendo agli studiosi moderni un'opera importante per comprendere il XVII secolo in tutta la sua complessità e ricchezza, che la Clélie, grazie all'influsso sempre più forte di Pellisson e al ricordo persistente del poeta Sarrasin, si prefigura sempre più come «l'expression de la théorisation d'une littérature galante en plein développement» (p. 13). 